\title{
Demographic study of patients with vertebral column trauma in North-West of Iran trauma center
}

Samad Shams Vahdati ${ }^{1}$, Ozgur tatli ${ }^{*}$, Seyedpooya Paknezhad ${ }^{3}$, Neda Parnianfard ${ }^{4}$, Ali Aygun ${ }^{5}$

1. Associate professor of emergency medicine, Road Traffic Injury Research Center, Department of Emergency Medicine, Tabriz University of Medical Sciences, Tabriz, Iran

2. Assistant professor of emergency medicine, emergency department, Karadeniz Technical University, Trabzon, Turkey

3. Resident of emergency medicine, Department of Emergency Medicine, Tabriz University of medical science, Tabriz,Iran

4. Student's research Committee of TUMS, Iranian Evidence-Based Medicine center of excellence, Tabriz University of Medical Sciences, Tabriz, Iran

5. emergency physician, emergency department, Ordu University education and research hospital

\begin{abstract}
Background: Spinal Traumatic injuries is the major damage which is associated with morbidity and mortality rates. In this study the epidemiological characteristics of trauma, spine and their relationship to outcome were investigated. Methods: In this cross sectional study, patients' information such as age, sex, type of injury, severity of injury, site of injury trauma who admitted to Imam Reza hospital from 29 march 2012 to 20 march 2014 were included. We used Chi-square tests to compare the types of injuries associated with the injury and regression methods. Results: The spinal trauma was identified in 105 cases, of which 9/61\% were male. $1.18 \%$ of patients with incomplete injury, $5 / 10 \% 4 / 71 \%$ damage and no injuries were full. $6 / 48 \%$ of vehicle accidents, 22 cases $(21 \%)$ of motorcycle accidents, 14 cases $3 / 13 \%$ due to the fall, the equivalent of $105 / 9 \%$ of pedestrian accidents, the equivalent of $57 / 4 \%$ injury 3 people with a knife and the rest of $9 / 2 \%$ were due to other causes. 6 people, equivalent to $2 / 9 \%$ were experiencing mortality. Type of injury, site of injury and injury severity was significantly associated with outcome. Conclusion: accidents caused by motor vehicles (cars and motorcycles) are the most common cause of trauma in spines in our country. Three factors as well as stable or unstable trauma, the severity of the initial injury and the injury as factors influencing outcome were obtained. According to the achievement of the emergency department in the early diagnosis, appropriate management such as surgery in preventing complications and improving outcome becomes more clear.
\end{abstract}

Key words: Trauma; Spine;

\section{Corresponding author:}

Ozgur Tatli

Assistant professor of emergency medicine, emergency department, Karadeniz Technical University, Trabzon, Turkey Adress: Universite Mh. Farabi Hastanesi Pk:61080 Ortahisar/Trabzon

Email: dr.ozgurtatli@ktu.edu.tr Tel: +9004623771183

Receive date: 2016-11-28 | Accept date: 2016-01-21 | Publish date: 2017-02-10

DOI: 10.7575/aiac.abcmed.17.05.01.04 


\section{Introduction}

Although Acute injuries of vertebral column are one of the uncommon complain which present to emergency department, but they are important due to their destructive and long-time morbidities. This kind of trauma is cost consuming with disabilities (1).

These injuries mostly occur in young people, with male to female ratios of 4:1. Car crush are the most common reason of vertebral column injuries and sport trauma is in second step. vertebral column trauma are one of the major reasons of mortality and morbidity in many countries. Vertebral column trauma and spinal cord injuries are two types of spinal injuries which cause disability, mortality and impose cost for the health care system (2).

One of the most important predicting indexes for decreasing this health problem is epidemiologic data to find the reasons and risk factors of vertebral column trauma; then it will possible to make rules, guidelines and design educational systems for at risk groups. To decrease this type of injury (3).

Spinal cord injuries based on their etiology divided to two groups, traumatic and nontraumatic. In general population traumatic injuries of spinal cord and vertebral column are more than non-traumatic ones. Traumatic injuries are in young adults of 16 to 30 and is $85 \%$ in males (4).

There are several factors which predict functional outcome of patients with spinal cord and vertebral column traumas. Also different studies explain the recovery process and revival of a neurologic findings (5).

Most spinal cord injuries are traumatic and most fractures of this column which resulted from crushes may lead to spinal cord injury. Sometimes spinal trauma resulted from spinal tension with fractured bone or ligaments (6). Vascular damage and ligament damages usually occurs in car collision injuries, motorcycle accidents, sever sport exercises, gunshot trauma, felling down from the height and stabs wounds (7).

In waters et al studies which was done to observe blunt $\&$ traumatic fractures of cervical spine, Prevalence of blunt traumatic cervical spine fractures (TCSF) was near to $1 / 5$ of fractures. In their study $\mathrm{C}_{2}$ was the most prevalent vertebra for fracture and $1 / 3$ of fractures were in low cervical vertebrae from $\mathrm{C}_{3}$ to $C_{7}$. Average age of patients was $36.1 \pm 17.2$, $29.1 \%$ of patients were low educated. Prevalent mechanism of trauma in fractures of $C_{1}-C_{7}$ vertebrae was motorcycle accidents and felling down from the height was the second one; in this patients had spine cord and spinal roots injury $13.3 \%$, 39.9\% respectively. Hospital mortality based on lower, upper and multiple fractures was $12.5 \%, 10.5 \%$ and $16.7 \%$ respectively and there wasn't any meaningful difference between groups mortality (8-10).

According to high prevalence of mortality and morbidity due to trauma in our country (11) and also vertebral trauma and lake of studies in demography of it in our area, we decided to gather patients data with vertebra trauma and get demography study on incidence of it and its outcome and if there is any relation between data.

\section{Materials and Methods:}

\section{Population:}

In this cross sectional descriptive study, patients with multiple trauma with spinal fracture and dislocation who came to emergency department of Imam Reza hospital as a north west trauma center of Iran, from 20 Mrach 2012 to 20 March 2014 were enrolled.

\section{Protocol:}

patient data such as age, Gender, Trauma Cause, portion of the spinal, the stability or 
instability of injury by imaging (radiography or $\mathrm{CT}$ ), the type of injury and its outcome including mortalilty, morbidity or improvement were collected by a structured questionnaire.

Exclusion criteria were: a) spinal cord impairment with a non traumatic cause, and b) initiation of treatments at another center.

The patients were divided into two groups as those with complete injuries and those with incomplete injuries according to the clinical findings during admission based on ASIAInternational Medical Society of Paraplegia (IMSOP) Impairment Scale (6). According to this index ASIA-IMSOP impairment score divided to 5 grades include Grade A contains complete spiral injury without any motor\& sensory function in sacral segments $S_{4}-S_{5}$.

Grade B: incomplete injury, Sensory but not motor function below the involved zone.

Grade C: motor function is preserved below the neurological level and more than 3 key muscles below the neurological level of injury have a muscle grade less than 3 .

Grade D: incomplete injury and motor function is preserved below the neurological level and at least 3 key muscles below the neurological level of injury have a muscle grade $\geq 3$.

\begin{tabular}{lll}
\hline Age & Number & percent \\
\hline $0-20$ & 31 & $29.5 \%$ \\
$20-40$ & 36 & $34.3 \%$ \\
$40-60$ & 23 & $21.9 \%$ \\
$60<$ & 15 & $14.3 \%$ \\
\hline
\end{tabular}

Table1: frequency of patients in age ranges

$36.9 \%$ were male in the range of 20 to 40 years and the majority of female $(35 \%)$ patients in the age range from zero to 20 years.

$48.6 \%(n=51)$ cases were car collision $21 \%$ $(n=22)$ of motorcycle accidents, $13.3 \% \quad(n=14)$
Grade E: without spinal involvement and normal motor and sensory function.

The patients were divided into four subgroups as $<20$ years of age, $20-40$ and $40-60$ years of age and $>60$ years of age. Data on the complete injury group and the incomplete injury group were compared.

\section{Analysis:}

All data of the patients were documented in the questionnaire and analyzed using the Statistical Package for the Social Sciences (SPSS) (version 15, SPSS Inc., Chicago, IL, USA. The relationship between the types of injury (complete and incomplete) and demographic characteristics was analyzed using chi-square test. Lesion sites, accompanying traumas, developing complications, and mortality rates were analyzed. For relation between data, Pierson regression was run. The level of statistical significance was accepted as $p<0.05$.

\section{Results}

In a study of 105 trauma patients admitted to the hospital, 65 cases of $61.9 \%$ male and 40 cases of $38.1 \%$ were women. Most of the patients were in 20-40 years old (figure 1 ). cases of fall from height, $5.9 \%(n=5)$ pedestrian accidents, $4.7 \%(n=5)$ of the injury with stabs and $2.9 \%(n=3)$ were due to other causes.

71.4\% $(n=75)$ patients did not have spinal cord injury (ASIA-E), in the other hand $10.5 \%$ $(n=11)$ had complete spinal injury (ASIA-A) and 
$18.1 \%(n=19)$ had incomplete cord injury (ASIA$B$ to D). 21\% ( $n=22)$ patients had multiple co morbidities such as diabetes or other chronic disease. $52.4 \% \quad(n=55)$ patients had stable fracture and $47.6 \% \quad(n=50)$ had unstable fracture. $59 \%(n=62)$ patients had permanent neurologic dysfunction, 33.4\% ( $n=35)$ were discharged and $7.6 \%(n=8)$ were died.

$59 \%(n=62)$ had cervical spinal finding (such as fracture, dislocation, disc herniation/ malposition or ligament protrusion to cord)., $26.7 \%(n=28)$ thoracic and $14.3(n=15)$ had lumbar vertebra trauma and finding.

In male, there is $72.4 \% \quad(n=47)$ patients discharged without any neurologic deficit,
$13.8 \%(n=9)$ patients had incomplete cord injury and $13.8 \%(n=9)$ had complete cord injury but in female $70 \%(n=28)$ patients were discharged and $22.5 \%(n=9)$ had incomplete cord injury and $7.5 \%(n=3)$ had complete cord injury; there is not any significant difference between two gender in kind of cord injury ( $p v=0.357)$.

The most cause of trauma in teenage and under 40 years old is car collision but in elderly the most one is falling (Table 2). in under 40 years old specially in under 20 years old most of vertebra fracture were stable but over 40 years old most of them unstable ( Table 3 ). in most of ages there is few complete cord injury (Table4).

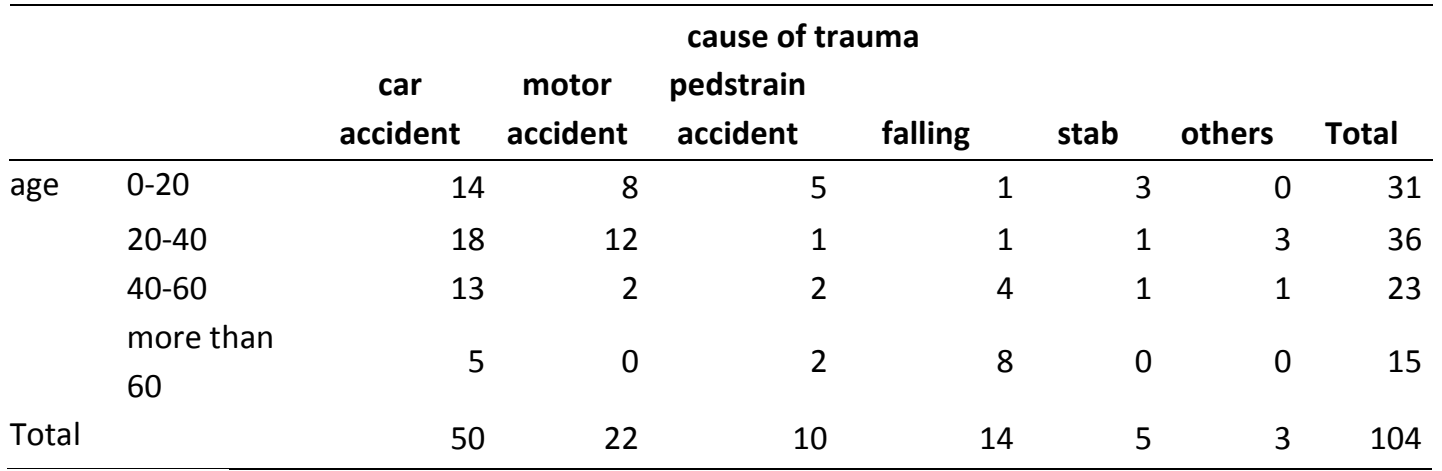

Table2: age and cause

\begin{tabular}{llrrr}
\hline & \multicolumn{4}{c}{ vertebral injury } \\
& & stable & unstable & Total \\
\hline age & $0-20$ & 25 & 6 & 31 \\
& $20-40$ & 17 & 19 & 36 \\
& $40-60$ & 9 & 14 & 23 \\
& more than & 3 & 12 & 15 \\
& 60 & 54 & 50 & 104 \\
\hline
\end{tabular}

Table 3: age and satblity of vertebra fracture

Trauma injuries are one of the main reasons for mortality and permanent morbidity especially among young people (12). Vertebral column and spinal cord injuries are also is one of the main causes of morbidity in young ages.
So that in some studies they constitute $60 \%$ of injuries among people under 40 and men are at higher risk of spinal cord injuries. In this study $63.8 \%$ of patients are under 40 also $61.9 \%$ are male. In male group most of the trauma cases 


\begin{tabular}{llrrrr}
\hline & \multicolumn{5}{c}{ spinal cord injury } \\
& & no & comple & un \\
injury & te & complete & Total \\
\hline age & $0-20$ & 23 & 5 & 3 & 31 \\
& $20-40$ & 27 & 3 & 4 & 34 \\
$40-60$ & 15 & 1 & 7 & 23 \\
& more & & & & \\
\multicolumn{1}{l}{ than 60} & 9 & 2 & 3 & 14 \\
Total & 74 & 11 & 17 & 102 \\
\hline
\end{tabular}

Table 4: age and cord injury

were at age range of $20-40$ years old and in female group most of them were 0 - 20 years old (13).

Also in Agrawel et al study shows that most cases were from 20-40 years old. Chacko et al founded that men in the age of 20-39 are the largest population in the vertebral trauma cases. Also no significant correlation was found between age, sex and outcome. In this study the most common causes of trauma were car collision and road traffic accidents (48.6\%) and motorcycle accidents (21\%).

In past studies it has been estimated that men are more likely to experience this trauma compared to women (13). In this study the main causes of trauma in men are car collision and motorcycle accidents and in female group the main causes are car collision, fall from height.

Also in past studies no significant gender dismantling was found in cause of trauma, but this study shows that the main cause in both gender is car collision. But in second step falling is more in female because of osteoporosis and other underline disease like osteoarthritis and etc $(6,14)$. Also lack of routine use of motorcycles by female is considered as a reason for less motorcycle accidents in female group.
Different studies use the ASIA or (complete damage, incomplete damage, no harm) classification to assess the intensity of spinal injuries (6).

In this study $71.4 \%$ of patients classified as no harm. $18.1 \%$ as incomplete damage and $10.5 \%$ as complete damage. Also different studies shown that the prevalence of incomplete damage is more than complete one. In this study significant correlation was found between type of injury and outcome. Different studies have investigated the location of spinal column injury effect; for example In Hagen and colleagues study distribution of spinal column injuries obtained: Cervical spinal $63.2 \%$ Thoracic spine Lumbusacral spine total $30.4 \%$ (15).

Several studies reported that lumbar spine are the most common site of involvement in fall from height and in vehicle accidents cervical spine injuries are the most common injury (16). Clearly, the causes of injury vary between countries, as they do between regions within a country and urban versus rural locations (17). On a global level traffic accidents involving motor vehicles, bicycles, or pedestrians account for the greatest number of SCls, typically $50 \%$ of all injuries (18).

In the review by sekhon, $45 \%$ of patients was in grade A of ASIA scoring and $15 \%$ in grade $B$, 
$10 \%$ in grade $C$ and $30 \%$ in grade $D(18)$; but in our study there was $10.5 \%$ of patients in garde $A$ and $18.1 \%$ were in grade B-D abd also $71.4 \%$ had no spinal injury and came in grade $E$.

\section{Limitation}

The most important spinal cord injury is the malpositioning and maloractice of pre hospital personnels in carring and transporting the trauma patients that cause secondary trauma (19); which is impossible for us to evaluate it. This mismanagement can decrease by primary trauma care courses but it is important to have course as a continue education courses (20, 21).

\section{Conclusion}

This study showed that accidents caused by motor vehicles (cars and motorcycles) in our country are the most important causes of spinal cord injury and vertebral trauma. As well as those under the age of 40 years are most influenced by this type of trauma.

\section{Authors contribution}

SSV designed the study. PP Data collection. AA performed the analysis and final evaluation. OT critically revised the article and study conduct. NP drafted the first copy of article.

\section{Funding}

This article had not any funding support.

\section{Conflict of Interest}

Authors have no conflict of interest.

\section{References}

1.Oliver, Susan. Oxford handbook of musculoskeletal nursing. Oxford University Press, 2009.

2. Ayers, Susan, et al., eds. Cambridge handbook of psychology, health and medicine. Cambridge University Press, 2007.

3. Grobbee, Diederick E., and Arno W. Hoes. Clinical epidemiology: principles, methods, and applications for clinical research. Jones \& Bartlett Learning, 2009.

4. Feigin, Valery L., et al. "Incidence of traumatic brain injury in New Zealand: a population-based study." The Lancet Neurology 12.1 (2013): 53-64.

5. Reier, Paul J. "Cellular transplantation strategies for spinal cord injury and translational neurobiology." NeuroRx 1.4 (2004): 424-451.

6. Bedbrook, George M. The care and management of spinal cord injuries. Springer Science \& Business Media, 2013. 7. Sommers, Marilyn S., and Ehriel Fannin. Diseases and disorders: A nursing therapeutics manual. FA Davis, 2014. 8.Waters, R.L., Adkins, R.H., Yakura, J.S., and Sie, I. (1993). Motor and sensory recovery following complete tetraplegia. Arch. Phys. Med. Rehabil. 74, 242-247.

9.Waters, R.L., Adkins, R.H., Yakura, J.S., and Sie, I. (1994a). Motor and sensory recovery following incomplete tetraplegia.

Arch. Phys. Med. Rehabil. 75, 306-311.

10.Waters, R.L., Adkins, R., Yakura, J., and Vigil, D. (1994b). Prediction of ambulatory performance based on motor scores derived from standards of the American Spinal Injury Association. Arch. Phys. Med. Rehabil. 75, 756-760. 11. Vahdati SS, GhafarZad A, Rahmani F, Panahi F, Rad AO. Patterns of road traffic accidents in north west of Iran during 2013 New Year Holidays: complications and casualties. Bulletin of emergency \& trauma. 2014 Apr;2(2):82. 12. Bydon, Mohamad, et al. "The current role of steroids in acute spinal cord injury." World neurosurgery 82.5 (2014): 848-854.

13. Agarwal P, Upadhyay P, Raja K. A demographic profile of traumatic and non-traumatic spinal injury cases: a hospital-based study from India. Spinal cord. 2007 Sep 1;45(9):597-602.

14. Scaer, Robert. The body bears the burden: Trauma, dissociation, and disease. Routledge, 2014. 
15. Hagen EM, Lie SA, Rekand T, Gilhus NE, Gronning M. Mortality after traumatic spinal cord injury: 50 years of follow-up. Journal of Neurology, Neurosurgery \& Psychiatry. 2010 Apr 1;81(4):368-73.

16. Jackson, Amie B., et al. "A demographic profile of new traumatic spinal cord injuries: change and stability over 30 years." Archives of physical medicine and rehabilitation 85.11 (2004): 1740-1748.

17. Tator $\mathrm{CH}$. Epidemiology and general characteristics of the spinal

cordinjuredpatient.In:TatorCH,BenzelEC,eds.ContemporaryManagement of Spinal Cord Injury: From Impact to Rehabilitation, 3rd ed. Park Ridge, IL: American Association of Neurological Surgeons, 2000:15-9

18. Sekhon LH, Fehlings MG. Epidemiology, demographics, and pathophysiology of acute spinal cord injury. Spine. 2001 Dec 15;26(24S):S2-12.

19. Ala A, Vahdati SS, Seyyedghiasi G. Evaluation of Trauma Patient Transport via Emergency Medical Services in Tabriz. Trauma monthly. 2012 May;14(1):262-3.

20. Amiri H, Gholipour C, Mokhtarpour M, Vahdati SS, Aghdam YH, Bakhshayeshi M. Two-day primary trauma care workshop: early and late evaluation of knowledge and practice. European Journal of Emergency Medicine. 2013 Apr 1;20(2):130-2.

21. Amiri H, Vahdati SS. Two-Day Primary Trauma Care Workshop-is it Beneficial?. Turkish Journal of Emergency Medicine. 2009;9(1):008-11. 